\title{
International Biobanking Summit V: Harmonizing Privacy Laws to Enable International Biobank Research
}

\author{
Marianna J. Bledsoe, Marianne Henderson?, Anne-Marie Tassé, and Bartha M. Knoppers ${ }^{4}$
}

$\mathrm{O}$ NE MAJOR CHALLENGE for global biobanking and international collaboration and data sharing has been the lack of harmonization among national regulations and policies that govern privacy and participant protections. This challenge was discussed at an International Biobanking Summit V (IBSV) held in Vienna, Austria, on September 14, 2016, as part of Europe Biobank Week. The Summit was sponsored by the Population Project in Genomics and Society (P3G; www.p3g.org), in collaboration with the Center of Genomics and Policy; the Institute for Bioethics, Health Policy and Law, University of Louisville; and the International Society for Biological and Environmental Repositories (ISBER, www.isber.org). The Summit was attended by more than 600 biobankers from across the world.

During the Summit, speakers representing a wide range of expertise, including lawyers, ethicists, and biobankers, presented the results of the studies that Prof. Bartha Knoppers and Mark Rothstein performed (NIH funded) on the privacy laws affecting biobanking in 22 countries, and the challenges of their implementation and harmonization. The results of these studies were published in the December $2015^{1}$ and June $2016^{2}$ issues of the Journal of Law Medicine and Ethics. Additional studies on this topic were also published in the June 2016 Special Issue of Biopreservation and Biobanking. ${ }^{3}$

Bartha Maria Knoppers, PhD, AdE, OC, OQ, FCAHS, Chair P3G, Director of the Centre of Genomics and Policy, Faculty of Medicine, Department of Human Genetics, McGill University, and Canada Research Chair in Law and Medicine, welcomed the meeting attendees and introduced the focus of the IBSV symposium. Anne-Marie Tassé, LLM, MA, PhD, Executive Director, P3G, Professional Associate, Centre of Genomics and Policy, Faculty of Medicine, Department of Human Genetics, McGill University, chaired both of the speaker sessions during IBSV.

The first speaker, Sirpa Soini, LLM, Senior legal adviser at Helsinki Biobank, Academic Medical Centre of HelsinkiHelsinki Biobank, Academic Medical Centre of Helsinki, presented about recent privacy and law reforms in Finland and their implications for biobanks. She discussed the need to balance the societal interest to improve healthcare and services based on specimen research with the risks to privacy and the right to self-determination regarding control and use of individual data. She explained that although it is critical to establish and maintain trust of research participants by communicating with them openly and educating them regarding biobanking, obtaining explicit consent for the use of samples in the medical care context is often infeasible. Instead, she suggested that Finland will likely implement an opt-out system of notification combined with an appropriate legal framework and appropriate governance system and that this may be the best approach for balancing societal "health" interests with those of research participants.

In the next presentation, Obiajulu Nnamuchi, LLM, LLD, Doctoral Researcher at Beazley Institute for Health Law \& Policy/Loyola University Chicago Law School, provided the Human Heredity and Health in Africa (H3Africa) perspective with regard to privacy protections related to human subjects research and biobanking in the countries participating in the project (http://h3africa.org, H3A). He described the purpose and goals of the project and addressed the difficulties associated with obtaining consent for biobanking and genomic research, particularly in the case of inadequately educated or illiterate populations. He concluded by discussing how longer periods of sample and data retention before sharing data in the project could provide the time necessary to recognize the contribution of African researchers.

David Townend, MPhil, PhD, Professor of Law and Legal Philosophy in Health, Medicine and Life Sciences at Maastricht University, NL, and Visiting Professor of Health Law, University of Lincoln, United Kingdom, provided an overview of the European General Data Protection Regulation and its implications for data sharing within and outside of the European Union (EU). He discussed the distinction between and the impact of an EU Research Directive and a Regulation and some of the provisions of the final Regulation. Issues

\footnotetext{
${ }^{1}$ ISBER Science Policy Committee Chair; Independent Consultant, Silver Spring, Maryland.

${ }^{2}$ Center of Global Health, National Cancer Institute, Bethesda, Maryland.

${ }^{3}$ Public Population Project in Genomics and Society (P3G), Montréal, Québec, Canada.

${ }^{4}$ Centre of Genomics and Policy, McGill University, Montréal, Québec, Canada.
} 
related to international data sharing were presented, including required procedural changes such as risk assessment, the concept of equal protections outside the EU, "pseudonymisation," various routes to lawful processing of data, and secondary processing of data. Dr. Townsend suggested that good practice and sector-specific tailoring might be employed as an avenue for lawful processing of data that may facilitate international data sharing while at the same time protecting the privacy of research participants.

The next speaker was Mark Rothstein, JD, State-of-theArt Speaker, Brandeis School of Law and School of Medicine, Chair of Law and Medicine and Founding Director of the Institute for Bioethics, Health Policy and Law at the University of Louisville School of Medicine. He presented the results of the NIH-supported study that he and Prof. Knoppers spearheaded on harmonizing privacy laws to enable international genomic research (1R01HG006838-01).

Prof. Rothstein explained the importance of international data sharing, as well as the importance of protecting privacy in biobank research. Focusing on the countries most active in human genomic and biobank research, he then presented findings from analyses that he and Prof. Knoppers recently published on the privacy laws of 22 countries, with extensive input from experts in each country. The results of these studies indicated that although there were some countries that had legislative coverage of biobanks either in statutes or biobank provisions, the legislative coverage of biobanks in the majority of countries is covered in general health, privacy, or other laws. Prof. Rothstein reported that some countries, such as Denmark and South Korea, require destruction or anonymization when research is complete. All countries that were included in the analysis require Institutional Review Board (IRB)/Research Ethics Board (REB) review or comparable review before researchers may access biobanks. In addition to IRB/REB review, some countries require a higher level of approval for access to genetic data (e.g., Brazil, France, and Israel). Prof. Rothstein then discussed the varying definitions related to various models of consent, as well as the different terms and varying definitions of terms related to identifiability.

Finally, Prof. Rothstein discussed the EU/U.S. Safe Harbor agreement that had been established to permit commercial flow of data between the EU and the United States and that was subsequently rescinded through a court challenge. He continued by presenting its recent replacement with the U.S. Privacy Shield and how the U.S. Privacy Shield permits the flow of commercial data between the EU and the United States. In conclusion, Prof. Rothstein suggested that in moving forward, it is important to maintain up-to-date and accessible compilations of key legal provisions, to continue to enact bilateral and multilateral agreements to facilitate international data sharing, to adopt voluntary guidelines, and to be poised to respond to new challenges that will protect the privacy of biobank research participants while at the same time promote international data sharing that will lead to advancements in research, medical care, and public health benefits.

The session concluded with an extensive interactive audience and panel discussion session, moderated by Marianne Henderson, MS, CPC, Senior Advisor for Division Resources for the National Cancer Institute's Division of Cancer Epidemiology and Genetics, Senior Advisor on biobanking to the NCI Center for Global Health and Chair of the ISBER Organizing Advisory Committee.

Discussions of privacy, confidentiality, and human participant protections for biobanking in the context of international biobanking collaborations are expected to remain prominent discussions in the field. These discussions will be continued at the next International Biobanking Summit VI to be held in Stockholm in conjunction with Global Biobank Week from September 13 to September 15, 2017 (http:// globalbiobankweek.org). We hope you will join us in these important and lively discussions!

\section{References}

1. Rothstein MA, Knoppers BM (guest eds). Harmonizing privacy laws to enable international biobank research, part I. Special symposium. J Law Med Ethics 2015;43:673-674.

2. Rothstein MA, Knoppers BM (guest eds). Part II: Harmonizing privacy laws to enable international biobank research. Special symposium. J Law Med Ethics 2016;44:1-172.

3. Tassé A-M, Bledsoe MJ (guest eds). Towards harmonization of the ethical, legal and social issues mosaic-An International Consortium Experience. Special issue. Biopreserv Biobank 2016;14:193-194. 